ISSN 0258-7122 (Print), 2408-8293 (Online)

Bangladesh J. Agril. Res. 41(1): 75-84, March 2016

\title{
EFFECT OF WEED EXTRACTS AGAINST PULSE BEETLE, Callosobruchus chinensis L. (COLEOPTERA: BRUCHIDAE) OF MUNG BEAN
}

\author{
M. A. AHAD 1 , M. K. NAHAR 2 , M. R. AMIN ${ }^{3}$ \\ S. J. SUH ${ }^{4}$ AND Y. J. KWON ${ }^{5}$
}

\begin{abstract}
The n-hexane extracts of the weeds 'bhatpata' Clerodendrum viscosum, 'kashiature' Cassia tora, 'dhakishak' Dryoptris filix-max, 'bonmorich' Croton bonpalandianum and 'ghagra' Xanthium strumarium were used to evaluate their effectiveness for suppressing pulse beetle, Callosobruchus chinensis reared on mung bean Vigna radiata grains. The investigations were done with 1, 2 and 4\% n-hexane extracts of the weeds and an untreated control. The weed extracts exhibited considerable effectiveness which varied with weed species, concentrations and exposure durations. The higher concentrations showed the higher rate of insect mortality, fecundity, adult emergence inhibition, and grain protection. The $\mathrm{LC}_{50}$ values of the extracts ranged from 5.3 to $7.8,4.7$ to 6.5 and 4.1 to $6.0 \mathrm{~g} / 100 \mathrm{ml}$ at 24,48 and 72 hours after treatment, respectively. The fecundity inhibition varied from 31.7 to $78.7 \%$, adult emergence inhibition from 33.8 to $81.1 \%$, and grain damage inhibition from 10.3 to $60.1 \%$ when 'bhatpata' with concentration of $1 \mathrm{~g} / 100 \mathrm{ml}$ and 'ghagra' with concentration of $4 \mathrm{~g} / 100 \mathrm{ml}$ were applied, respectively. Among the tested weeds, ghagra $(4 \mathrm{~g} / 100 \mathrm{ml})$ showed better efficacy against $C$. chinensis compared to other tested extracts and may be suggested to control pulse beetle and protection of mung bean grains.
\end{abstract}

Keywords: Adult emergence, bruchids, fecundity, grain damage, toxicity, weed extracts.

\section{Introduction}

The pulse beetle, Callosobruchus chinensis L. (Coleoptera: Bruchidae) is a serious pest of mung bean and many other pulse grains in the tropics (Roy et al., 2012a). The larvae of this pest penetrate into the pulse grains and feed endosperms, thus lead to damage grains as well as deteriorate nutritional value and germination capacity (Roy et al., 2014). Different microorganisms, especially fungi develop in the infested grains and eventually make it unfit for human consumption and propagation (Deeba et al., 2006).

Protection of pulse grains in the storage from the attack of $C$. chinensis mostly relied on synthetic insecticides like fumigation with methyl bromide and

\footnotetext{
${ }^{1 \& 2}$ Department of Entomology, Hajee Mohamed Danesh Science and Technology University, Dinajpur, Bangladesh, ${ }^{3}$ Department of Entomology, Bangabandhu Sheikh Mujibur Rahman Agricultural University, Gazipur, Bangladesh, ${ }^{4}$ School of Applied Biosciences, Kyungpook National University, Daegu, Korea, ${ }^{5}$ Institute of Plant Medicine, Kyungpook National University, Daegu, Korea.
} 
phosphine. These chemicals undoubtedly protect the grains but their excessive and inadvertent use created serious health hazards, environment pollution, cause ozone depletion and resistance to insects (Kim et al., 2003). These problems demand the need for restriction of such chemicals to ensure pesticide free foodstuffs (Daglish, 2008). Therefore, environmentally safe and convenient methods such as the use of plant extracts, oils, leaf powders and pressurized carbon dioxide and temperature management techniques are the growing interest to replace synthetic pesticides (Yuya et al., 2009).

Insecticidal activities of the plants have been intensively investigated and demonstrated promising for control of field and stored grain pests. Plant derived chemicals are hazard free and possess bitter substances which may show toxic, repellent, antifeedant, and growth and progeny inhibition activity against insect pests (Roy et al., 2005; Roy et al., 2014). Many plant-derived materials have been proved as toxic and growth regulators against stored products insects (Cosimi et al., 2009). Plant lectins are biodegradable insecticidal agents that possessed deleterious effects on the survival, growth, oviposition and reproduction of stored grain insect pests (Oliveira et al., 2011). The leaf extracts of ghagra Xanthium strumerium revealed insecticidal effectiveness against $C$. chinensis reared on black gram grains.

Plant powders, extracts and oils are a rich source of bioactive chemicals which reveal toxic effect and produce odors that repel adult beetles. The weed plants are excellent store of medicine and possess toxic chemicals, but little investigations have been done on their use in insect pest management. This study was designed with n-hexane extracts of five indigenous weed species to evaluate their effectiveness on mortality, fecundity and adult emergence inhibition of $C$. chinensis reared on mung bean grains. In addition, an assessment of the grain damage inhibition with the extracts was also determined.

\section{Materials and Method}

\section{Insect culture}

Mass culture of the insect was done on mung bean (Vigna radiata; Leguminosae) grains at an ambient temperature of $27 \pm 2{ }^{\circ} \mathrm{C}$ and $80 \pm 5 \% \mathrm{RH}$ in the laboratory of the Department of Entomology, Hajee Mohammad Danesh Science and Technology University (HSTU), Dinajpur, Bangladesh. Ten pairs of adult beetles (1-3 day old) along with the food were placed in 11 glass jar. The mouth of the jar was fastened with muslin cloth with rubber band and kept 7 days in the laboratory for mating and oviposition of the insects. The beetles were removed from the jar and the eggs laid on the pulses were allowed to hatch. To study bioassay, insect rearing was repeated until $3^{\text {rd }}$ generations with a view to ensuring enough population without affecting original culture. 


\section{Collection and preparation of weed sample}

The weed species 'bhatpata', Clerodendrum viscosum Vent. (Verbenaceae), 'kashiature', Cassia tora L. (Leguminosae), 'dhakishak', Dryoptris filix-max L. (Polypodiaceae), 'bonmorich', Croton bonplandianum Baill. (Euphorbiacae) and 'ghagra', Xanthium strumarium L. (Asteraceae) were collected from the road side of HSTU, collected in plastic bags and transported to the Entomology Laboratory. The weeds were washed with tap water and air dried for 7 days in the shade. Furthermore, the weeds were dried in an oven at $50-60^{\circ} \mathrm{C}$ for $24 \mathrm{~h}$ to obtain constant weight. The weeds were powdered mechanically by using an electric blender (Braun Multiquick Immersion Hand Blender, B White Mixer MR $5550 \mathrm{CA}$, Germany), passed through 40 mesh screen and stored at $28{ }^{\circ} \mathrm{C}$ in tightly-closed dark glass bottles.

\section{Preparation of $n$-hexane extracts from the weeds}

Dried powder of each weed species was separately extracted in n-hexane. For each preparation, $10 \mathrm{~g}$ powder was macerated in a 2.51 capacity glass bottle using 11 n-hexane (96\% analytical pure) for 7 days. To be sure for complete extraction, the sample was shaken for $72 \mathrm{~h}$ using an electric shaker. The extract was filtered and the filtrate was considered as $1 \%$ concentration $(1 \mathrm{~g} / 100 \mathrm{ml})$. Similarly, 2 and $4 \%$ extracts were prepared and stored in a refrigerator at $4{ }^{\circ} \mathrm{C}$ until bioassay.

\section{Contact toxicity test}

Three day-old adult beetles were chilled for a period of 10 minutes in a refrigerator at $5{ }^{\circ} \mathrm{C}$, and then $1 \mu \mathrm{l}$ of an extract was applied to the dorsal thorax of the beetles with a micro pipette. Fifty insects were used for each treatment and untreated control treatment was applied with n-hexane only. The insects were then transferred into $9 \mathrm{~cm}$ diameter Petri dishes (10 insects / Petri dish) that contained $100 \mathrm{~g}$ mung bean grains. Number of insect mortality in each Petri dish was recorded at 24, 48 and $72 \mathrm{~h}$ after treatment and \% mortality was calculated. Data of toxicity studies were corrected for untreated control mortality according to Schneider-Orelli's (1947) formula as mortalities in the control treatment ranged between 5 and $20 \%$.

Corrected mortality $(\%)=\frac{\% \text { Mortalityin treatments }-\% \text { Mortalityin control }}{100-\% \text { Mortalityin control }} \times 100$

Toxicity ratios (TR) were calculated using the formula: $\mathrm{TR}=\mathrm{LC}_{50}$ and /or $\mathrm{LC}_{95}$ of the extract with less toxicity / $\mathrm{LC}_{50}$ and /or LC95 of the other extract, individually (Gusmao et al., 2013).

\section{Fecundity inhibition test}

In each glass container $100 \mathrm{~g}$ grains were put and the predetermined extract concentrations were distinctly added to the containers with pipette, and subjected 
to manual agitation for $2 \mathrm{~min}$. Thereafter, the grains were placed in Petri dishes and five pairs of newly emerged beetles were released in each Petri dish. After 7 days, the numbers of eggs laid by the females on mung bean grains in the Petri dishes were counted by using hand lens. There were three replications for each extract concentration and a control treatment was made with untreated grains. The fecundity inhibition $(\% \mathrm{FI})$ of each extract concentration was calculated using the following formula:

$\% \mathrm{~F} 1=\frac{\text { Eggs laid in control grains }- \text { Eggs laid in treated grains }}{\text { Eggs laid in control grains }} \times 100$

\section{Observation on adult insect emergence and grain damage inhibition}

The weed extracts were poured distinctly into the glass containers which had mung bean grains. The extracts were mixed with the grains and then air dried. The grains were placed in different Petri dishes and five pairs of newly emerged beetles were released in each Petri dish. After 7 days the beetles were removed from the Petri dishes and the Petri dishes along with pulse grains were kept in the laboratory. Daily observation was made after one month of egg laid because bruchids adult usually emerge after 30 days of egg-laid. Observation was continued up to 15 days and removed the newly emerged beetles. A control treatment consisting of untreated grains was taken into account and each treatment replicated thrice. The adult emergence inhibition rate (\%IR) was calculated by using the following formula:

$\% \mathrm{IR}=\frac{\text { No. of insects in control grains }- \text { No. of insects in treated grains }}{\text { No. of insects in control grains }} \times 100$

Number of damaged grains in each Petri dish was counted and percent grain damage inhibition (\%DI) was calculated by the following formula:

$\% \mathrm{DI}=\frac{\text { No. of damaged grains in control }- \text { No. of damaged grains in treatments }}{\text { No. of damaged grains in control }} \times 100$

\section{Statistical analysis}

Probit analysis was employed in analyzing the dose-mortality response. $\mathrm{LC}_{50}$ and $\mathrm{LC}_{95}$ values and their fiducial limits were estimated. Data of the fecundity, adult emergence and grain damage inhibition were expressed as mean \pm SD (Standard Deviation). Significance of mean differences among the treatments were statistically compared using GLM at 5\% probability level. The individual pair wise comparisons were made using Tukey's HSD posthoc analysis through SPSS (IBM SPSS statistics 21). 


\section{Results and Discussion}

The extracts of the weeds at $24 \mathrm{~h}$ after treatment showed toxicity effect on adult C. chinensis (Table 1). Contact toxicity data revealed $\mathrm{LC}_{50}$ and $\mathrm{LC}_{95}$ values from $5.3(4.2-9.3)$ to $7.8(5.3-23.4)$ and $10.2(7.3-20.2)$ to $16.9(10.6-57.7) \mathrm{g} / 100 \mathrm{ml}$, respectively. Results demonstrated that the $\chi^{2}$ values of the data differed significantly $(p<0.05)$ and 'ghagra' extract was found to be the most effective. Its concentration response curve showed the steepest slope which indicated that small variations in the concentrations induced greater responses in mortality. The order of mortality activity of the weed extracts at $24 \mathrm{~h}$ post treatment showed 'ghagra' > 'bonmorich' > 'dhakishak' > 'kashiature' > 'bhatpata'.

Table 1. Toxicity effect of five weed extracts on adult Callosobruchus chinensis exposed to $24 \mathrm{~h}$ post treatment

\begin{tabular}{l|c|c|c|c|c|c}
\hline \multicolumn{1}{c}{ Weed plant } & $\begin{array}{c}\text { Slope }( \pm \\
\text { S.E) }\end{array}$ & LC50 (95\% fl) & $\mathrm{TR}_{50}$ & LC95a $(95 \% \mathrm{fl})$ & $\mathrm{TR}_{95}$ & $\chi^{2}(\mathrm{df})$ \\
\hline Bhatpata & $0.20 \pm 0.05$ & $7.8(5.3-23.4)$ & - & $16.9(10.6-57.7)$ & - & $28.8(13)$ \\
Kashiature & $0.22 \pm 0.05$ & $6.5(4.4-41.2)$ & 1.20 & $15.3(9.1-118.4)$ & 1.10 & $36.8(13)$ \\
Dhakishak & $0.28 \pm 0.05$ & $5.9(4.4-11.6)$ & 1.32 & $12.2(8.4-27.4)$ & 1.39 & $28.8(13)$ \\
Bonmorich & $0.31 \pm 0.05$ & $5.3(4.2-9.7)$ & 1.47 & $11.0(7.7-23.0)$ & 1.54 & $34.0(13)$ \\
Ghagra & $0.33 \pm 0.05$ & $5.3(4.2-9.3)$ & 1.47 & $10.2(7.3-20.2)$ & 1.67 & $36.6(13)$ \\
\hline
\end{tabular}

Each datum represents the mean of five replicates, each set up with 10 adults $(n=50)$. Concentrations are expressed as $\mathrm{g} / \mathrm{ml}$. fl stands for fiducial limits. 'Different concentrations (1, 2 and $4 \mathrm{~g} / 100 \mathrm{ml})$. SE= Standards Error.

Table 2. Toxicity effect of five weed extracts on adult Callosobruchus chinensis exposed to $48 \mathrm{~h}$ post treatment

\begin{tabular}{l|c|c|c|c|c|c}
\hline \multicolumn{1}{|c}{ Weed plant } & $\begin{array}{c}\text { Slope }( \pm \\
\text { S.E) }\end{array}$ & LC50 (95\% fl) & TR $_{50}$ & LC95 $(95 \% f l)$ & TR $_{95}$ & $\chi^{2}(\mathrm{df})$ \\
\hline Bhatpata & $0.13 \pm 0.04$ & $6.5(4.7-13.9)$ & - & $18.7(12.3-46.2)$ & - & $12.9(13)$ \\
Kashiature & $0.19 \pm 0.04$ & $6.1(4.4-16.5)$ & 1.07 & $14.9(9.5-47.7)$ & 1.26 & $25.4(13)$ \\
Dhakishak & $0.26 \pm 0.05$ & $5.6(4.6-7.6)$ & 1.16 & $11.9(9.3-17.6)$ & 1.57 & $13.9(13)$ \\
Bonmorich & $0.29 \pm 0.05$ & $4.9(3.9-8.5)$ & 1.33 & $10.8(7.7-21.9)$ & 1.73 & $31.5(13)$ \\
Ghagra & $0.33 \pm 0.05$ & $4.7(4.1-5.7)$ & 1.38 & $9.6(7.9-12.5)$ & 1.95 & $17.3(13)$ \\
\hline
\end{tabular}

Each datum represents the mean of five replicates, each set up with 10 adults $(n=50)$. Concentrations are expressed as $\mathrm{g} / \mathrm{ml}$. fl stands for fiducial limits. ${ }^{\text {a Different }}$ concentrations (1, 2 and 4g/100 ml). SE= Standards Error.

The toxicity of the weed extracts against pulse beetle at $48 \mathrm{~h}$ post treatment showed $\mathrm{LC}_{50}$ and $\mathrm{LC}_{95}$ values from 4.7 (4.1-5.7) to 6.5 (4.7-13.9) and 9.6 (7.912.5) to $18.7(12.3-46.2) \mathrm{g} / 100 \mathrm{ml}$, respectively (Table 2). The results indicated that the $\chi^{2}$ values of the data were significantly different $(\mathrm{p}<0.05)$. The 'ghagra' extract revealed the lowest $\mathrm{LC}_{50}$ and $\mathrm{LC}_{95}$ values and the concentration response 
curve of this plant also showed the steepest slope. The order of toxicity of the weeds at $48 \mathrm{~h}$ post treatment was 'ghagra' > 'bonmorich' > 'dhakishak' > 'kashiature' > 'bhatpata'.

When the n-hexane extracts of the weeds were examined for toxicity against $C$. chinensis at $72 \mathrm{~h}$ post treatment, significant differences $(\mathrm{p}<0.05)$ were observed (Table 3). The insecticidal activities of the weeds showed that their $\mathrm{LC}_{50}$ and $\mathrm{LC}_{95}$ ranged from 4.1 (3.4-5.7) to 6.0 (4.4-12.7) and 9.0 (6.9-14.3) to 18.6 (12.246.5) $\mathrm{g} / 100 \mathrm{ml}$, respectively. Among the treatments, ghagra revealed the most toxic effect as it showed the lowest $\mathrm{LC}_{50}$ and $\mathrm{LC}_{95}$ values as well as steepest slope of the concentration curve. The order of toxicity of the weeds was 'ghagra' > 'bonmorich' > 'dhakishak' > 'kashiature' > 'bhatpata'.

Table 3. Toxicity effect of five weed extracts on adult Callosobruchus chinensis exposed to $72 \mathrm{~h}$ post treatment

\begin{tabular}{l|c|c|c|c|c|c}
\hline \multicolumn{1}{|c}{ Weed plant } & $\begin{array}{c}\text { Slope } \\
( \pm \mathrm{S} . \mathrm{E})\end{array}$ & $\begin{array}{c}\mathrm{LC}^{\mathrm{a}} 50 \\
(95 \% \mathrm{fl})\end{array}$ & $\mathrm{TR}_{50}$ & LC95 $^{\mathrm{a}}(95 \% \mathrm{fl})$ & $\mathrm{TR}_{95}$ & $\chi^{2}(\mathrm{df})$ \\
\hline Bhatpata & $0.14 \pm 0.04$ & $6.0(4.4-12.7)$ & - & $18.6(12.2-46.5)$ & - & $13.5(13)$ \\
Kashiature & $0.25 \pm 0.04$ & $4.6(3.6-8.3)$ & 1.30 & $11.3(7.8-24.5)$ & 1.65 & $31.2(13)$ \\
Dhakishak & $0.28 \pm 0.04$ & $4.6(3.7-7.2)$ & 1.30 & $11.1(8.1-19.8)$ & 1.68 & $22.2(13)$ \\
Bonmorich & $0.31 \pm 0.04$ & $4.2(3.4-7.1)$ & 1.43 & $10.0(7.1-20.7)$ & 1.86 & $38.1(13)$ \\
Ghagra & $0.36 \pm 0.05$ & $4.1(3.4-5.7)$ & 1.46 & $9.0(6.9-14.3)$ & 2.07 & $28.9(13)$ \\
\hline
\end{tabular}

Each datum represents the mean of five replicates, each set up with 10 adults $(n=50)$. Concentrations are expressed as $\mathrm{g} / \mathrm{ml}$. $\mathrm{fl}$ stands for fiducial limits. ${ }^{\text {aDifferent }}$ concentrations (1,2 and 4g/100 ml). SE= Standards Error.

The toxicity of the extracts clearly showed that insect mortality varied with weed species, extract concentrations and exposure periods. The weed species acted as a valuable source of insecticide. The ingredients of these weeds may have the ability to inject into the body of the beetles and dysfunction their nutritional balance, thus caused mortality. Adedire and Akinneye (2004) reported the mortality effect of Tithonia diversifolia flower extracts on $C$. maculatus. Botanical insecticides offer broad spectrum toxic substances that interrupt insect's normal physiology and behavior, and influence on their feeding, mating, oviposition and mortality (Fouad et al., 2014).

The fecundity inhibition effects of the weed extracts on $C$. chinensis are presented in Table 4. The weed species $\left(\mathrm{F}_{4,30}=8.9, \mathrm{p}<0.001\right)$, extract concentrations $\left(\mathrm{F}_{2,30}=91.3, \mathrm{p}<0.001\right)$ and interaction of weed species and extract concentrations $\left(\mathrm{F}_{8,30}=2.6, \mathrm{p}<0.05\right)$ had significant effects on the fecundity. The extracts showed $31.7 \pm 8.3$ to $78.7 \pm 1.2 \%$ fecundity inhibition and the most promising result was obtained by $4 \%$ 'ghagra'. It may be that the weeds have compounds with broad spectrum action affecting the life stages of 
the insect and inhibit their oviposition. Ambrósio et al. (2008) reported that the plant Mexican tournesol Tithonia diversifolia possessed sesquiterpene lactones which inhibited the oviposition of herbivore insects. The fecundity inhibition effects of the stem and flower extracts of kair Capparis decidua on caper $C$. chinensis have been reported by Upadhyay et al. (2006).

Table 4. Effect of five weed extracts on the fecundity inhibition (\% mean \pm SD) of Callosobruchus chinensis

\begin{tabular}{l|cccc}
\hline \multirow{2}{*}{ Weed plant } & \multicolumn{3}{|c}{$\%$ Fecundity inhibition at different extract concentration. } \\
\cline { 2 - 4 } & $1 \mathrm{~g} / 100 \mathrm{ml}$ & $2 \mathrm{~g} / 100 \mathrm{ml}$ & $4 \mathrm{~g} / 100 \mathrm{ml}$ \\
\hline Bhatpata & $31.7 \pm 8.3 \mathrm{bB}$ & $60.6 \pm 2.8 \mathrm{aAB}$ & $66.6 \pm 7.1 \mathrm{aA}$ \\
Kashiature & $48.1 \pm 5.7 \mathrm{cA}$ & $57.6 \pm 6.9 \mathrm{abB}$ & $68.1 \pm 1.3 \mathrm{aA}$ \\
Dhakishak & $49.1 \pm 6.3 \mathrm{bA}$ & $60.9 \pm 2.0 \mathrm{abAB}$ & $66.2 \pm 6.8 \mathrm{aA}$ \\
Bonmorich & $49.3 \pm 1.5 \mathrm{bA}$ & $65.3 \pm 2.0 \mathrm{aAB}$ & $68.3 \pm 6.1 \mathrm{aA}$ \\
Ghagra & $52.7 \pm 3.2 \mathrm{cA}$ & $67.5 \pm 1.5 \mathrm{bA}$ & $78.7 \pm 1.2 \mathrm{aA}$ \\
\hline
\end{tabular}

Values followed by the same small letter(s) on the same row or by the same capital letter(s) in the same column are not significantly different, as assessed by Tukey HSD Posthoc $(\mathrm{p} \leq 0.05)$. SE $=$ Standard Error.

Table 5. Effect of five weed extracts on the adult emergence inhibition (\% mean \pm SD) of Callosobruchus chinensis

\begin{tabular}{l|c|c|c}
\hline \multirow{2}{*}{\multicolumn{1}{c}{ Weed plant }} & \multicolumn{3}{|c}{ \% Adult beetle emergence inhibition at different extract } \\
& \multicolumn{3}{|c}{ concentration. } \\
\cline { 2 - 4 } & $1 \mathrm{~g} / 100 \mathrm{ml}$ & $2 \mathrm{~g} / 100 \mathrm{ml}$ & $4 \mathrm{~g} / 100 \mathrm{ml}$ \\
\hline Bhatpata & $33.8 \pm 4.4 \mathrm{cD}$ & $48.2 \pm 3.5 \mathrm{abC}$ & $63.5 \pm 2.5 \mathrm{aC}$ \\
Kashiture & $35.8 \pm 4.9 \mathrm{cCD}$ & $54.6 \pm 2.0 \mathrm{abC}$ & $73.8 \pm 1.5 \mathrm{aB}$ \\
Dhakishak & $48.9 \pm 4.8 \mathrm{bBC}$ & $64.5 \pm 5.4 \mathrm{aB}$ & $66.5 \pm 3.4 \mathrm{aC}$ \\
Bonmorich & $53.0 \pm 5.8 \mathrm{bB}$ & $72.5 \pm 3.4 \mathrm{aAB}$ & $78.2 \pm 2.4 \mathrm{aAB}$ \\
Ghagra & $76.9 \pm 5.1 \mathrm{cA}$ & $78.2 \pm 2.4 \mathrm{bA}$ & $81.1 \pm 1.4 \mathrm{aA}$ \\
\hline
\end{tabular}

Values followed by the same small letter(s) on the same row or by the same capital letter(s) in the same column are not significantly different, as assessed by Tukey HSD Posthoc $(\mathrm{p} \leq 0.05)$. SE $=$ Standard Error.

The weed species $\left(\mathrm{F}_{4,30}=86.7, \mathrm{p}<0.001\right)$, extract concentrations $\left(\mathrm{F}_{2,30}=\right.$ $139.2, \mathrm{p}<0.001)$ and interaction of weed species and extract concentrations $\left(F_{8,30}=9.7, p<0.001\right)$ showed significant effect on the adult beetle emergence (Table 5). Adult beetle emergence inhibition in different treatments varied from $33.8 \pm 4.4$ to $81.1 \pm 1.4 \%$. Among the treatments, $4 \%$ ghagra and $1 \%$ bhatpata revealed the highest and lowest level of inhibition, respectively.

Nennah (2011) reared $T$. castaneum and $R$. dominica on ground wheat grains mixed with methanolic extracts of harmel Peganum harmala seed and found abnormal larvae and pupae, as well as dose dependent adult emergence inhibition of the insects. In the present study, the weed extracts showed remarkable effect 
on the adult emergence of $C$. chinensis. The extracts revealed 33.8 to $81.1 \%$ adult emergence inhibition and the inhibitory activity of the extracts increased with increased concentration. Roy et al. (2012b) observed 37.0\% adult emergence inhibition of $C$. chinensis with $4 \%$ aqueous extract of common cocklebur, $X$. strumarium.

Table 6 showed that the extracts possessed grain damage inhibition against $C$. chinensis. The effects of weed species $\left(\mathrm{F}_{4,30}=22.8, \mathrm{p}<0.001\right)$, extract concentrations $\left(\mathrm{F}_{2,30}=92.6, \mathrm{p}<0.001\right)$ and interaction of weed species and extract concentrations $\left(\mathrm{F}_{8,30}=3.9, \mathrm{p}<0.01\right)$ differed significantly. Grain damage inhibition among the treatments varied from $10.3 \pm 7.2$ to $60.1 \pm 3.8 \%$, and the highest and lowest inhibition levels were attained by $4 \%$ ghagra and $1 \%$ bhatpata, respectively. The present findings indicated that the weed extracts had potential effect to control stored grain pest. The toxicity of the extracts might hamper food ingestion and feeding activity of the pests. Tavares et al. (2011) observed that the extracts of tournesol $T$. diversifolia reduced egg hatching of Spodoptera frugiperda and inhibited grain damage of Triticum aestivum both in the field and storage conditions.

Table 6. Effect of five weed extract on the grain damage inhibition (\% mean \pm SD) of mung bean from the attack of Callosobruchus chinensis

\begin{tabular}{l|cccc}
\hline \multirow{2}{*}{ Weed plant } & \multicolumn{3}{c}{ \% Grain damage inhibition at different extract concentration. } \\
\cline { 2 - 4 } & $1 \mathrm{~g} / 100 \mathrm{ml}$ & $2 \mathrm{~g} / 100 \mathrm{ml}$ & $4 \mathrm{~g} / 100 \mathrm{ml}$ \\
\hline Bhatpata & $10.3 \pm 7.2 \mathrm{cB}$ & $26.8 \pm 2.7 \mathrm{bBC}$ & $50.2 \pm 3.1 \mathrm{aA}$ \\
Kashiture & $18.9 \pm 7.3 \mathrm{bAB}$ & $38.7 \pm 5.7 \mathrm{aB}$ & $39.6 \pm 3.6 \mathrm{aB}$ \\
Dhakishak & $20.6 \pm 6.8 \mathrm{cAB}$ & $24.4 \pm 6.5 \mathrm{abC}$ & $38.6 \pm 5.5 \mathrm{aB}$ \\
Bonmorich & $23.3 \pm 6.3 \mathrm{bAB}$ & $52.2 \pm 5.5 \mathrm{aA}$ & $59.8 \pm 3.9 \mathrm{aA}$ \\
Ghagra & $28.6 \pm 2.8 \mathrm{bA}$ & $57.0 \pm 1.3 \mathrm{aA}$ & $60.1 \pm 3.8 \mathrm{aA}$ \\
\hline
\end{tabular}

Values followed by the same small letter(s) on the same row or by the same capital letter(s) in the same column are not significantly different, as assessed by Tukey HSD Posthoc $(\mathrm{p} \leq 0.05)$. $\mathrm{SE}=$ Standard Error.

Grain protection from the attack of insect pests without hampering environment is the main objective of the application of botanical pesticides. Plant materials possessed antifeedant substances and deterred insects from feeding and damaging grains (Amin et al., 2000; Shahjahan and Amin, 2000; Roy et al., 2010). The studied weed extracts protected mung bean grains from the attack of $C$. chinensis to a significant level (10.3 to $60.1 \%)$. This finding indicated that the weed extracts inhibited feeding behavior of the pest and protected the grains. Other authors have obtained similar results with different plant and insect species. Rahman and Talukder (2006) reported that 3\% acetone extract of lagundi Vitex negundo revealed good protection for black gram seeds against $C$. chinensis infestation. 
Plant materials are easy to manufacture and application and the studied weed species are very common in the rural areas of Bangladesh. The mixtures of weed materials with rapid and slow action insecticide might be useful in the protection of stored grains. In the present study, 4\% 'ghagra' extract demonstrated the highest mortality and inhibited fecundity, adult emergence, as well as protected grains from infestation. So, the findings suggested that the 'ghagra' leaf extract as an alternative means of chemical insecticides may be used to save mung bean grains from the attack of $C$. chinensis. Further studies are needed to identify the toxic compounds, cost of treatment, effect of the odor and flavor on processed grains, toxicity of extract on non-target species including human and development of formulation for effective application.

\section{References}

Adedire, C. O. and J. O. Akinneye. 2004. Biological activity of tree marigold, Tithonia diversifolia, on cowpea seed bruchid, Callosobruchus maculatus (Coleoptera: Bruchidae). Ann. Appl. Biol. 144:185-189.

Ambrósio, S. R., Y. Oki, V.C.G. Heleno, J. S. Chaves, P.G.B.D. Nascimento, J. E. Lichston, M. G. Constantino, E. M. Varanda and F. B. Costa. 2008. Constituents of glandular trichomes of Tithonia diversifolia: relationships to herbivory and antifeedant activity. Phytochem. 69: 2052-2060.

Amin, M. R., M. Shahjahan, H. F. El-Taj, T.M.T. Iqbal and M.A. Hossain. 2000. Use of akanda, biskatali and neem leaves as botanical insecticides against lesser grain borer. Bangladesh J. Entomol. 10:1-13.

Cosimi, S., E. Rossi, P. L. Cioni and A. Canale. 2009. Bioactivity and qualitative analysis of some essential oils from Mediterranean plants against stored-product pests: evaluation of repellency against Sitophilus zeamais Motschulsky, Cryptolestes ferrugineus (Stephens) and Tenebrio molitor L. J. Stored Prod. Res. 45:125-132.

Daglish, G. 2008. Impact of resistance on the efficacy of binary combinations of spinosad, chloropyrifos-methyl and s-methoprene against five stored-grain beetles. $J$. Stored Prod. Res. 44: 71-76.

Deeba, F., M. Sarwar and R. D. Khuhro. 2006. Varietal susceptibility of mungbean genotypes to pulse beetle, Callosobruchus analis (Fabricius) (Coleoptera:Bruchidae). Pak. J. Zool. 38: 265-268.

Fouad, H. A., L. R. D. A. Faroni, W. S. Tavares, R. C. Ribeiro, S.S. Freitas and J.S. Zanuncio. 2014. Botanical extracts of plants from the Brazilian cerrado for the integrated management of Sitotroga cerealella (Lepidoptera: Gelechiidae) in stored grain. J. Stored Prod. Res. 57: 6-11.

Gusmão, N. M. S., J. V. Oliveira, D. M. A. F. Navarro, K. A. Dutra, W. A. Silva, M. J. A. Wanderley. 2013. Contact and fumigant toxicity and repellency of Eucalyptus citriodora Hook., Eucalyptus staigeriana F., Cymbopogon winterianus Jowitt and Foeniculum vulgare Mill. essential oils in the management of Callosobruchus maculatus (FABR.) (Coleoptera: Chrysomelidae, Bruchinae). J. Stored Prod. Res. 54: 41-47. 
Kim, S. I., C. Park, M. H. Ohh, H. C. Cho and Y. J. Ahn. 2003. Contact and fumigant activities of aromatic plant extracts and essential oils against Lasioderma serricorne (Coleoptera: Anobiidae). J. Stored Prod. Res. 39: 11-19.

Nennah, G. 2011. Toxicity and growth inhibitory activities of methanol extract and the $\beta$ carboline alkaloids of Peganum harmala L. against two coleopteran stored-grain pests. J. Stored Prod. Res. 47: 255-261.

Oliveira, C. F. R., L. A. Luz, P. M. G. Paiva, L. C. B. B. Coelho, S. Marangoni and M.L.R. Macedo. 2011. Evaluation of seed coagulant Moringa oleifera lectin (cMoL) as a bioinsecticidal tool with potential for the control of insects. Process Biochem. 46: 498-504.

Rahman, A. and F. A. Talukder. 2006. Bioefficacy of some plant derivatives that protect grain against the pulse beetle, Callosobruchus maculatus. J. Insect Sci. 6:1-10.

Roy, B., B. C. Sarker, M. R. Amin, B. C. Roy and S. Jalal. 2010. Bio-efficacy of shiyalmutra leaf extract against rice weevil. J. Sci. Technol. (Dinajpur). 8:1-5.

Roy, B., M.R. Amin, M.N. Uddin, A.T.M.S. Islam, M.J. Islam and B.C. Halder. 2005. Leaf extracts of shiyalmutra (Blumea lacera) as botanical insecticides against lesser grain borer and rice weevil. J. Biol. Sci. 5: 201-204.

Roy, B., M. R. Amin, S. Jalal, B. C. Sarker. 2012a. Bioefficacy of blood leaf plant extracts against pulse beetle, Callosobruchus chinensis (Coleoptera: Bruchidae). Bangladesh J. Entomol. 22: 69-77.

Roy, B., M. R. Amin, S. Jalal, Y. J. Kwon, S. J. Suh. 2014. Evaluation of common cocklebur Xanthium strumarium leaf extract as post-harvest grain protectant of black gram against pulse beetle Callosobruchus chinensis (Coleoptera: Bruchidae) and isolation of crude compound. Ent. Res. 44: 254-261.

Roy, B., S. Jalal, B. C. Sarker, M. R. Amin, Y. H. Jeon and I. J. Chun. 2012b. Evaluation of insecticidal activities of common cocklebur fruit extract against pulse beetle Callosobruchus chinensis (Coleoptera: Bruchidae). Korean J. Appl. Entomol. 51: 325-329.

Schneider-Orelli, O. 1947. Entomologisches Praktikum: Einführung in die land- und forstwirtschaftliche Insektenkunde. Sauerländer Aarau, Germany.

Shahjahan, M. and M. R. Amin. 2000. Evaluation of some plant extracts against rice weevil, Sitophilus oryzae L. J. Asiat. Soc. Bangladesh Sci. 26: 213-222.

Tavares, W. S., I. Cruz, F. G. Fonseca, N. L. Gouveia, J. E. Serrão and J.C. Zanuncio. 2011. Deleterious activity of natural products on postures of Spodoptera frugiperda (Lepidoptera: Noctuidae) and Diatraea saccharalis (Lepidoptera: Pyralidae). J. Biosci. 65: 412-418.

Upadhyay, R. K., L. Rohatgi, M. K. Chaubey and S. C. Jain. 2006. Ovipositional responses of the pulse beetle, Bruchus chinensis (Coleoptera: Bruchidae) to extracts and compounds of Capparis decidua. J. Agric. Food Chem. 54: 9747-9751.

Yuya, A. I., A. Tadesse, F. Azerefegne and T. Tefere. 2009. Efficacy of combining niger seed oil with malathion $5 \%$ dust formulation on maize against the maize weevil, Sitophilus zeamais (Coleoptera: Curculionidae). J. Stored Prod. Res. 45: 67-70. 